\title{
Information seeking behaviour of the professoriate in selected federal universities in southwest Nigeria
}

\author{
Simeon Nwone ${ }^{1}$ and Stephen Mutula ${ }^{2}$ \\ simeonnwone@gmail.com ORCID: orcid.org/0000-0002-0737-3702 \\ mutulas@ukzn.ac.za ORCID: orcid.org/0000-0003-3776-8104
}

\begin{abstract}
Received: 30 March 2018
Accepted: 6 August 2018

This article is derived from a PhD awarded at the University of KwaZulu-Natal in 2018 that investigated information seeking behaviour of the professoriate in the social sciences and humanities in selected federal universities in southwest Nigeria. The study was a descriptive survey of the professoriate in the social sciences and humanities. An adapted questionnaire was used to collect data from 246 professors. Data was analysed using descriptive statistics. The results revealed that professoriate need information mainly for developing contents used for teaching and conducting research. They seek information for teaching and research in online databases and electronic journals, while depending on textbooks and printed journals. They make use mainly of laptop and desktops to access information. They frequently share research information in subscription-based and fee-based open access journals. The professoriate generally exhibit positive attitude towards electronic resources.
\end{abstract}

Keywords: Information seeking behaviour, information needs, information sharing, electronic information resources, professoriate

\section{Introduction}

Information seeking behaviour is the deliberate search for information out of a need to meet some goals (Wilson 2000: 49). The process of seeking confines the person to either interact with manual information systems such as a library, or with computer-based systems like the internet (Wilson 2000: 49). It is a broad term encompassing the ways individuals articulate their information needs, seek, evaluate, select, and use the needed information (Savolainen 2011). Purposeful information seeking begins by users selecting information sources and applying different criteria to value and prioritise such sources (Bronstein 2010).

Information plays a significant role in the professional lives of the professoriate in university environments with regard to task completion and everyday decision-making (Singh \& Satija 2007). For the purpose of this research, the professoriate is a group of academics distinguished through long-term intellectual contribution to teaching, research and community engagements (Carrell \& West 2010); the term may also mean the rank or position of a university professor (Theall \& Franklin 2001). Studies have shown that faculty members need information mostly for teaching and research (Ezeh 2013, Ofori-Dwumfuo \& Addo 2012, Salau \& Saingbe 2008, Ugah 2008). Laila \& Mumtaz (2010) report that faculty staff, especially at the professoriate level, are heavily dependent on books, journals, conferences, subject experts and colleagues to meet their information needs. The World Wide Web, search engines, and electronic resources such as electronic journals, online databases, e-books, emails, online catalogues, listserv and web portals among others have become important sources of information for the professoriate (Xuemei 2010).

The professoriate in the context of Nigeria comprises the readers (assistant professors), associate professors and professors of a university. The professoriate in different academic fields exhibit different information behaviour since they have different information horizons. According to Savolainen and Kari (2004), a person's information horizons vary across situations, contexts and social networks. For example, the professoriate in law might prefer textbooks and case files from the library to online databases (Thanuskodi 2009). In contrast, the professoriate in science may prefer electronic databases since they depend on current information in their field (Engel, Robbins \& Kulp 2011, Hemminger, Lu, Vaughan \& Adams 2007). This article focuses on the information behaviour of the professoriate with regard to how they seek, access and use electronic resources in the social sciences and humanities at the University of Ibadan, University of Lagos and Obafemi Awolowo University (OAU) in Nigeria.

1. Simeon Nwone is a Postdoctoral Fellow, Information Studies Programme, College of Humanities, University of KwaZulu-Natal, South Africa

2. Stephen Mutula is Professor in the Information Studies Programme and Acting Deputy Vice-Chancellor: College of Humanities, University of KwaZulu-Natal, South Africa 
The focus on the social sciences and humanities is because these disciplines offer interdisciplinary, cross-disciplinary and transdisciplinary fields of study. Focusing on the social sciences and the humanities in this paper is expected to provide an in-depth understanding of information behaviour of the professoriate from several fields of study (Al-Suqri 2011, Meho \& Tibbo 2003, Meho \& Haas 2001). The three Nigerian universities chosen for this study are the oldest in southwest Nigeria and are ranked in the top three universities by the Nigeria Universities Commission (2015). While a number of studies (De Groote, Shultz \& Blecic 2014, Aforo \& Lamptey 2012, Bhatti 2010, Thanuskodi 2009, Majid, Ali Anwar \& Eisenschitz 2000) have focused on information seeking behaviour of faculty members in general, specific attention has not been given to the professoriate; Xuemei (2010) notes that studies on information seeking behaviour of the professoriate remain scarce in empirical literature. This study therefore examines the information seeking behaviour of the professoriate in the three selected federal universities in Nigeria, with the aim of discovering their information needs, how they seek, access and share information, and their attitude towards electronic information resources. Understanding their information behaviour will assist the academic library to design information services to suit the information needs of this group to support their teaching and research and change their perceptions in a dynamic information environment where electronic information resources are becoming more and more prevalent. Furthermore, this article contributes to the development of institutional policies and strategies that promote access to print and electronic information resources by the professoriate.

\section{Literature Review}

The empirical literature was reviewed after a search on scholarly databases and search engines on the information seeking behaviour of faculty members. Since the study investigates the information seeking behaviour of the professoriate, attention was given to studies that had professoriate in their population.

Xuemei (2010) used a qualitative approach to investigate the information behaviour of eight professors, five associate professors, eight assistant professors and nine doctoral students in the social science and humanities in the Unites States of America (USA). The result revealed that social science faculty members used periodicals more often than their humanities counterparts, while humanities faculty utilised books as their primary sources of information. In all, electronic resources accounted for $58 \%$ of materials used in satisfying their research needs, while print sources accounted for $42 \%$ of their research needs. Despite the general preference for electronic information resources, individual differences existed among the professorial ranks and discipline. A Teaching and Learning professor who used print resources in teaching and research found it difficult to adapt to electronic information resources because of his anxiety over information technologies. A professor of History explained the continued reliance on print resources and the importance of the availability and accessibility of old manuscripts to the discipline. In African Studies, a professor accustomed to using print resources in his research found it difficult to use the electronic resources in the university library, since the nature of his research relied heavily on fieldwork.

A study by Marouf \& Anwar (2010) investigated the information seeking behaviour of ten professors, twenty-five associate professors, and nineteen assistant professors in Kuwait using a quantitative approach. The results showed that the majority of the professoriate were heavily dependent on print sources for teaching and research. Since the language of teaching in Kuwait is Arabic, the professoriate in the university were limited to using print sources written in Arabic due to scarcity of online databases that offer scholarly information in Arabic. Thanuskodi (2009) used a quantitative approach to study the information behaviour of faculty members at the Central Law Faculty in Salem, India. Among the fifty-six respondents were five professors. The result showed that professoriate relied more on textbooks and law reports for information seeking, while the use of online databases was significantly lower, indicating that professoriate in Law relied more on print resources than electronic sources. In a similar study in a law faculty in Ghana, Aforo and Lamptey (2012) observed that faculty members use law reports, law journals and text to seek information, further reinforcing the reliance on print resources than electronic resources by those in the faculty.

Meho and Haas (2001), in a study on the information seeking behaviour of social science faculty members studying stateless nations across countries of the USA, United Kingdom, Germany, Canada, Australia, France, Italy, Netherlands, Switzerland and Turkey, showed that besides using traditional methods, social science professors use the World Wide Web and email for locating relevant information, suggesting that these faculty members are aware of and utilise new information technology to support their research. The participants of the study were six assistant professors, nine associate professors and five professors. Environmental variables seemed to play a crucial role in their familiarity with technology since faculty members in developed countries are more technological adept than those in developing countries. Rupp-Serrano and Robbins (2013) used a mixed methods approach to examine the information seeking habits of education faculty members in the USA. The outcome revealed that scholarly journals were the most preferred resource for research, followed by internet resources, and books. Scanning current issues of journals, attending professional conferences, following references or leads from an article or item of interest, and personal communication were the most 
frequently means of staying current. Of the respondents, $26 \%$ were professors, $25 \%$ associate professors and $23 \%$ assistant professors, while $13 \%$ were adjunct faculty, instructors and lecturers.

Folorunso's (2014) study on the information seeking behaviour of social sciences scholars in a research institute in Nigeria revealed that research scholars need information for research and to keep abreast of developments in their fields of study. To meet their information needs, they rely on journals and online sources and they attend conferences. The study showed different patterns of electronic information resource usage among academic ranks. In particular, junior research fellows use electronic resources about twice as much as research professors to satisfy their research needs. Presumably, younger researchers are more comfortable with emerging technologies in relation to older researchers. The result revealed that scholars younger than fifty years of age approached electronic information resources with more enthusiasm than their older counterparts. The respondents comprised ten professors, eleven associate professors, thirteen senior research fellows, fourteen research fellows and two junior research fellows.

Ismail, Mahesar and Idrees (2017) carried out a study on electronic resource preferences of faculty members at the University of Peshawar in Pakistan. The findings showed that assistant professors used electronic information sources (EIS) more than associate professors and professors, and those who had more recent publications to their names were more experienced in using EIS than those who had fewer. One of the major findings of the study was that most of the faculty members used EIS frequently and preferred e-journals to print journals.

The literature reviewed examines the information seeking behaviour of faculty members in general, with little attention being paid to the professoriate as a unique group. Moreover, most studies on information behaviour of faculty members in general and the professoriate in particular are from western and Middle Eastern countries.

\section{Methodology}

A descriptive survey design was used to examine the information seeking behaviour of the professoriate. The population of the study comprised 246 members of the professoriate (see Table 1) from the social sciences and humanities at the universities of Ibadan, Lagos and OAU. A census survey, which ensured the complete enumeration of the study participants, was used to collect the required data. A questionnaire consisting of both self-structured and adapted questions from previous studies was used to collect quantitative data from the professoriate. Items on information needs were adapted from Ezinwanyi and Opeke (2013); items on information seeking, access, and use of electronic information sources were adapted from Xuemei (2010); and, items on attitude were from Larbi-Apau and Moseley (2012). Adapting questions from previous empirical studies give credence to the external validity of the instrument (Shadish, Cook \& Campbell 2002). Professional research assistants were used to collect data from the professoriate through individual visits to their offices. The research assistants were familiar with the three universities and have good experience in data collection. Collecting data from the professors was a daunting process, due to their regular unavailability in their offices and often-busy schedules, thereby prolonging the period of data collection, which took approximately seven months, from January to July 2016.

At the University of Lagos, eighty-six questionnaires were distributed, forty-eight collected and forty found fit for data analysis. This represents a success rate of $46.5 \%$. At the University of Ibadan, ninety-one questionnaires were distributed, seventy-six collected and seventy found fit for analysis, representing a success rate of $76.9 \%$. At the Obafemi Awolowo University, sixty-nine questionnaires were distributed, sixty were retrieved and fifty-five were found fit for analysis, representing a success rate of $79.7 \%$. In all, 246 questionnaires were distributed, 184 were collected and 165 questionnaires were found fit and coded for data analysis, representing an overall success rate of $67 \%$. The data was analysed using descriptive statistics with the Statistical Package for the Social Sciences (SPSS).

Table 1 Population of the study

\begin{tabular}{lc}
\hline Faculty: Social Science and Humanities & Total no. in the professoriate \\
\hline University of Lagos & 86 \\
University of Ibadan & 91 \\
Obafemi Awolowo University & 69 \\
Total & $\mathbf{2 4 6}$ \\
\hline
\end{tabular}

\section{Results}

In the section that follows, the study results are described according to demographics of the participants, their information needs, sources used, access to information, information sharing habits and attitudes towards electronic resources. 


\subsection{Demographic characteristics of respondents}

The results of the demographic attributes of the professoriate are presented in Table 2.

Table 2 Demographic characteristics of the professoriate $(\mathrm{N}=165)$

\begin{tabular}{|c|c|c|c|}
\hline Variables & Measurement & Freq & Percent \\
\hline \multirow[t]{3}{*}{ Professoriate } & University of Ibadan & 70 & 42.4 \\
\hline & Obafemi Awolowo University & 55 & 33.3 \\
\hline & University of Lagos & 40 & 24.2 \\
\hline \multirow[t]{4}{*}{ Faculty } & Arts & 65 & 39.4 \\
\hline & Social Sciences & 55 & 33.3 \\
\hline & Education & 43 & 26.1 \\
\hline & Law & 2 & 1.2 \\
\hline \multirow[t]{3}{*}{ Rank } & Full professor & 105 & 63.6 \\
\hline & Readers (assistant professor) & 41 & 24.8 \\
\hline & Associate professor & 19 & 11.5 \\
\hline
\end{tabular}

Table 2 shows that the University of Ibadan had the highest number of respondents (seventy; 42.4\%), next is the Obafemi Awolowo University (fifty-five; 33.3\%), while the University of Lagos had the least (forty; 24.2\%). The distribution of professoriate according to faculty showed that majority of the respondents were from faculties of Arts (sixty-five; 39.4\%), followed by Social Sciences (fifty-five; 33.3\%) and Education (forty-three; 26.1\%), while Law faculties (two; $1.2 \%$ ) recorded the fewest respondents. The ranks of the respondents revealed that the majority $(105 ; 63.6 \%)$ were full professors, while readers (assistant professors) were forty-one (24.8\%), and associate professors were nineteen (11.5\%).

\subsection{Information needs of the professoriate}

The results on the information needs of the professoriate are presented in Table 3.

Table 3 Information needs of the professoriate $(\mathrm{N}=165)$

\begin{tabular}{|c|c|c|c|c|c|c|}
\hline \multirow{2}{*}{ Information needs of professoriate } & \multicolumn{2}{|c|}{ VI } & \multicolumn{2}{|c|}{ SI } & \multicolumn{2}{|c|}{ NI } \\
\hline & $\mathbf{N}$ & $\%$ & $\mathbf{N}$ & $\%$ & $\mathbf{N}$ & $\%$ \\
\hline Developing contents used for teaching & 165 & 100 & - & - & - & - \\
\hline Conducting research & 165 & 100 & - & - & - & - \\
\hline Keep abreast of current developments in my field & 165 & 100 & - & - & - & - \\
\hline I need educational information & 142 & 86.1 & 15 & 9.1 & 8 & 4.8 \\
\hline I need socio-cultural information & 93 & 56.4 & 59 & 35.8 & 12 & 7.3 \\
\hline I need political information & 48 & 29.1 & 104 & 63 & 13 & 7.9 \\
\hline I need information for planning & 36 & 21.8 & 113 & 68.5 & 16 & 9.7 \\
\hline I need religious information & 35 & 21.2 & 58 & 35.8 & 69 & 41.8 \\
\hline I need economic information & 30 & 18.2 & 105 & 63.6 & 30 & 18.2 \\
\hline I need information for coordinating & 27 & 16.4 & 116 & 70.3 & 21 & 12.7 \\
\hline I need financial management information & 14 & 8.5 & 88 & 53.3 & 63 & 36.2 \\
\hline I need information for directing & 12 & 7.3 & 120 & 72.7 & 24 & 14.5 \\
\hline I need parenting information & 12 & 7.3 & 38 & 23 & 113 & 68.5 \\
\hline I need health information & 10 & 6.1 & 116 & 70.3 & 39 & 23.6 \\
\hline I need information for decision making & 7 & 4.2 & 139 & 84.2 & 19 & 11.5 \\
\hline I need marketing information & 7 & 4.2 & 57 & 34.5 & 99 & 60 \\
\hline I need legal information & 5 & 3.0 & 72 & 43.6 & 88 & 53.3 \\
\hline I need technical information & 4 & 2.4 & 73 & 44.2 & 88 & 53.3 \\
\hline
\end{tabular}

$\mathrm{VI}$ = Very Important; SI = Slightly Important; $\mathrm{NI}$ = Not Important 
The information needs of the professoriate were measured in terms of the types of information they require to meet their teaching and research goals. The results showed that all the professoriate considered information for developing contents used for teaching, information for conducting research, and information to keep abreast of current developments in their fields of study as a 'very important' information need. Educational information was considered 'very important' by $142(86.1 \%)$ respondents, 'slightly important' by fifteen $(9.1 \%)$, and 'not important' by eight $(4.8 \%)$ respondents. Sociocultural information was considered 'very important' by ninety-three $(56.4 \%)$ respondents, 'slightly important' by fifty-nine $(35.8 \%)$ and' not important' by twelve (7.3\%). Political information was next important, with forty-eight $(29.1 \%)$ of the professoriate considering it to be 'very important', $104(63 \%)$ as 'slightly important', while only thirteen (7.9\%) considered it 'not important'. Information for planning and for religious purposes were rated, respectively, by $113(68.5 \%)$ and fiftyeight $(35.8 \%)$ as 'slightly important', sixteen $(9.7 \%)$ and sixty-nine $(41.8 \%)$ as 'not important'. Economic information followed in importance, with thirty (18.2\%) of the respondents stating it is 'very important', while $105(63.6 \%)$ and thirty $(18.2 \%)$ considered it 'slightly important' and 'not important' respectively. Parenting and health information were considered, respectively, by twelve $(7.3 \%)$ and ten $(6.1 \%)$, as 'very important', thirty-eight $(23 \%)$ and $116(70.3 \%)$ as 'slightly important', and $113(68.5 \%)$ and thirty-nine (23.6\%) as 'not important'. Legal and technical information were considered of least importance among the professoriate with only five (3\%) and four $(2.4 \%)$ respondents considering them 'very important'.

\subsection{Information sources used by the professoriate}

The information sources used by the professoriate to seek information for teaching and research are captured in Table 4.

Table 4 Information sources used by the professoriate for teaching and research

\begin{tabular}{|c|c|c|c|c|c|c|c|c|}
\hline \multirow{2}{*}{$\begin{array}{l}\text { Information Sources for teaching and } \\
\text { research }\end{array}$} & \multicolumn{2}{|c|}{ Always } & \multicolumn{2}{|c|}{ Occasionally } & \multicolumn{2}{|c|}{ Rarely } & \multicolumn{2}{|c|}{ Never } \\
\hline & $\mathbf{N}$ & $\%$ & $\mathbf{N}$ & $\%$ & $\mathbf{N}$ & $\%$ & $\mathbf{N}$ & $\%$ \\
\hline \multicolumn{9}{|l|}{ Electronic resources } \\
\hline Online databases & 127 & 77 & 37 & 22.4 & 1 & 0.6 & - & - \\
\hline Electronic journals & 119 & 71.5 & 42 & 25.5 & 5 & 3.0 & - & - \\
\hline Web portals & 87 & 52.7 & 48 & 29.1 & 23 & 13.9 & - & - \\
\hline Web sites & 84 & 50.9 & 53 & 32.1 & 23 & 13.9 & - & - \\
\hline Electronic mail & 16 & 9.7 & 33 & 20 & 91 & 55.2 & 7 & 4.2 \\
\hline Online catalogues & 9 & 5.5 & 84 & 50.9 & 52 & 31.5 & - & - \\
\hline Listservs & - & - & 12 & 7.3 & 118 & 71.5 & - & - \\
\hline FTP & - & - & 3 & 1.8 & 18 & 10.9 & 137 & 83 \\
\hline \multicolumn{9}{|l|}{ Media } \\
\hline Newspaper & 3 & 1.8 & 129 & 77.6 & 34 & 20.6 & & \\
\hline Radio & 2 & 1.2 & 62 & 37.6 & 81 & 49.1 & 13 & 7.9 \\
\hline TV & - & - & 84 & 50.9 & 75 & 45.5 & 6 & 3.6 \\
\hline \multicolumn{9}{|l|}{ Print resources } \\
\hline Journal articles & 165 & 100 & - & - & - & - & - & - \\
\hline Textbooks & 163 & 98.8 & 2 & 1.2 & - & - & - & - \\
\hline Encyclopaedia & 69 & 41.8 & 83 & 50.3 & 13 & 7.9 & - & - \\
\hline Maps & 31 & 18.8 & 19 & 11.5 & 77 & 46.7 & - & - \\
\hline Magazine & 4 & 2.4 & 62 & 37.6 & 84 & 50.9 & 14 & 8.5 \\
\hline \multicolumn{9}{|l|}{ Interpersonal sources } \\
\hline Interaction with colleagues & 101 & 61.2 & 55 & 33.3 & 7 & 4.2 & - & - \\
\hline Interaction with friends & 2 & 1.2 & 26 & 15.8 & 97 & 58.8 & 25 & 15.2 \\
\hline \multicolumn{9}{|l|}{ Academic gathering } \\
\hline Conference proceedings & 71 & 43 & 88 & 53.3 & 4 & 2.4 & - & - \\
\hline Seminars & 50 & 30.3 & 107 & 64.8 & 4 & 2.4 & - & - \\
\hline Workshops & 43 & 26.1 & 100 & 60.6 & 19 & 11.5 & - & - \\
\hline
\end{tabular}


The results revealed that the majority of the professoriate 'always' seek information for teaching and research in online databases $(127 ; 77 \%)$ and electronic journals $(119 ; 71.5 \%)$, while thirty-seven $(22.4 \%)$ and forty-two $(25.5 \%)$, respectively, 'occasionally' use online databases and electronic journals to seek information for teaching and research purposes. The professoriate that 'rarely' use online databases (one; $0.6 \%$ ) and electronic journal (five; $3 \%$ ) are few in number. Those that 'always' used web portals (eighty-seven; 52.7\%) to seek information for teaching and research are more than those that use websites (eighty-four; 50.9\%), electronic mail (sixteen; $9.7 \%$ ) and online catalogues (nine; $5.5 \%$ ). 'Occasional' uses of online catalogues (eighty-four; $50.9 \%$ ) are reported more than 'occasional' uses of websites (fifty-three; 32.1\%), web portals (forty-eight; 29.1\%), electronic mail (thirty-three; 20\%), listservs (twelve; $7.3 \%$ ) and file transfer protocol (FTP) (three; 1.8\%) for teaching and research. A significant majority $(137 ; 83 \%)$ of the professoriate 'never' use FTP to seek information for teaching and research purposes.

In the media category, newspaper (three; 1.8\%), radio (two; 1.2\%) and television (TV) are hardly 'always' used by the professoriate for teaching and research, compared to a larger number that 'occasionally' use newspaper (129; 77.6\%), radio (sixty-two; 37.6\%) and TV (eighty-four; 50.9\%) for teaching and research. Those that 'rarely' use newspaper, radio and TV account for thirty-four (20.6\%), eighty-one (49.1\%) and seventy-five (45.5\%) of the respondents, respectively.

In the print resources category, journal articles are 'always' used by all the professoriate for seeking information for teaching and research, followed by textbooks (163; 98.8\%), encyclopaedia (sixty-nine; $41.8 \%$ ), maps (thirty-one; 18.8\%), and magazines (four; $2.4 \%$ ). 'Occasional' usage of encyclopaedia (eighty-three; 50.3\%) for teaching and research was more compared to textbooks (two; 1.2\%), maps (nineteen; 11.5\%) and magazines (sixty-two; $37.6 \%$ ). Those that 'rarely' use magazines (eighty-four; 50.9\%) for teaching and research outweighed those that 'rarely' use encyclopaedia and textbooks for teaching and research. Only fourteen (8.5\%) of the respondents never used magazines for teaching and research.

In the interpersonal sources category, interaction with colleagues is 'always' used by the majority $(101 ; 61.2 \%)$ of the professoriate to seek information for teaching and research, while fifty-five (33.3\%) 'occasionally' use it for the same purpose. There are few (seven; 4.2\%) reported cases of 'rare' use of interaction with colleagues for teaching and research. Interaction with friends (two; $1.2 \%$ ) is hardly 'always' used by the professoriate for teaching and research, only 'occasionally' used by twenty-six (15.8\%) and 'rarely' used by ninety-seven (58.8\%) for teaching and research.

In the academic gathering category, conference proceedings are 'always' used by the majority (seventy-one; $43 \%$ ) of the respondents for seeking information for teaching and research, followed by seminars (fifty; $30.3 \%$ ) and workshops (forty-three; $26.1 \%$ ). More of the professoriate also tend to seek information for teaching and research 'occasionally' in conference proceedings (eighty-eight; 53.3\%), seminars (107; 64.8\%), and workshops (100;60.6\%). The number of professoriate that rarely seek information for teaching and research in conference proceedings (four; $2.4 \%$ ), seminars (four; $2.4 \%$ ) and workshops (nineteen; 11.5\%) are few.

\subsection{Professoriate access to information}

Professoriate access to information was measured by the place or location and the digital devices used by the professoriate to access information.

\subsubsection{Locations used to access information by the professoriate}

The results on the location the professoriate used when accessing information are presented in Table 5.

Table 5 Locations used to access information

\begin{tabular}{lcc|cc}
\hline \multirow{2}{*}{ Locations used to access information } & \multicolumn{2}{c|}{ Yes } & \multicolumn{3}{c}{ No } \\
\cline { 2 - 5 } & N & $\%$ & N & $\%$ \\
\hline Office & 165 & 100 & - & - \\
From home & 153 & 92.7 & 12 & 7.3 \\
Library & 57 & 34.5 & 108 & 65.5 \\
\hline
\end{tabular}

The results show that all the professoriate access information for teaching and research from their offices, while a vast majority (153; 92.7\%) accessed information for teaching and research from their homes. The use of the university library by the professoriate to access information was low (fifty-seven; $34.5 \%$ ).

\subsubsection{Digital devices used by the professoriate to access information}

The results on the digital devices used by the professoriate to access information are presented in Table 6 . 
Table 6 Digital devices used to access information

\begin{tabular}{lccc|cc|cc}
\hline \multirow{2}{*}{ Digital devices used to access information } & \multicolumn{2}{c|}{ Frequently } & \multicolumn{2}{c|}{ Occasionally } & \multicolumn{2}{c}{ Rarely } \\
\cline { 2 - 7 } & $\mathbf{N}$ & $\%$ & $\mathbf{N}$ & $\%$ & $\mathbf{N}$ & $\%$ \\
\hline Laptop & 155 & 93.9 & 7 & 4.2 & - & - \\
Desktop computer & 140 & 84.8 & 23 & 13.9 & - & 73.6 \\
Smartphone & 41 & 24.8 & 52 & 31.5 & 72 & 75.2 \\
Palmtop & 2 & 1.2 & 28 & 17 & 124 & 72.4 \\
Mobile phone & - & - & 17 & 10.3 & 136 & 82.4 \\
\hline
\end{tabular}

The results show that the professoriate used varied electronic devices to access information. The laptop (155; $93.9 \%$ ) was 'frequently' used by the professoriate to access information followed by the desktop (140; $84.8 \%$ ). The smartphone is used 'frequently' by only forty-one $(24.8 \%)$ and sometimes by fifty-two $(31.5 \%)$ of the professoriate to access information. The palmtop was less 'frequently' (two; $1.2 \%)$ but 'occasionally' used by only twenty-eight (17\%) to access information. The mobile phone was never 'frequently' used but 'occasionally' used by only seventeen (10.3\%) of the professoriate to access information.

\subsection{Professoriate information sharing}

Professoriate information sharing was measured by the types of information shared by the professoriate and the medium used to share their research outcomes (research visibility).

\subsubsection{Types of information shared by the professoriate}

The types of information shared by the professoriate are presented in Table 7.

Table 7 Type of information shared by the professoriate

\begin{tabular}{lccc|c|cc}
\hline \multirow{2}{*}{$\begin{array}{l}\text { Type of Information shared by the } \\
\text { Professoriate }\end{array}$} & \multicolumn{2}{c|}{ Frequently } & \multicolumn{2}{c|}{ Occasionally } & \multicolumn{2}{c}{ Rarely } \\
\cline { 2 - 7 } & $\mathbf{N}$ & $\%$ & $\mathbf{N}$ & $\%$ & $\mathbf{N}$ & $\%$ \\
\hline Research information & 165 & 100 & - & - & - & - \\
Academic information & 163 & 98.8 & 2 & 1.2 & - & - \\
Political information & 30 & 18.2 & 116 & 70.3 & 17 & 10.3 \\
Social information & 24 & 14.5 & 120 & 72.7 & 21 & 12.7 \\
Economic information & 13 & 7.9 & 130 & 78.8 & 22 & 13.3 \\
Business information & 9 & 5.5 & 32 & 19.4 & 124 & 75.2 \\
Legal information & 2 & 1.2 & 12 & 7.3 & 151 & 91.5 \\
Personal information & 2 & 1.2 & 32 & 19.4 & 131 & 79.4 \\
Medical information & 1 & 0.6 & 43 & 26.1 & 121 & 73.3 \\
Technical information & - & - & 37 & 22.4 & 128 & 77.8 \\
\hline
\end{tabular}

The results show that the vast majority of the professoriate 'frequently' share research $(100 \%)$ and academic information (98.8\%). Political information is more 'occasionally' $(116 ; 70.3 \%)$ than 'frequently' shared (thirty; $18.2 \%)$. Social and economic information follow a similar pattern, 'occasionally' shared by $120(72.7 \%)$ and $130(78.8 \%)$ of the respondents respectively compared with twenty-four $(14.5 \%)$ and thirteen $(7.9 \%)$ who 'frequently' share their research information. Business, legal, personal, and technical information are less 'frequently' shared, which explains why legal (151; 91.5\%), personal $(131 ; 79.4 \%)$, technical $(128 ; 77.8 \%)$, business $(124 ; 75.2 \%)$ and medical $(121 ; 73.3 \%)$ information, in that order, are rarely shared by the professoriate.

\subsubsection{Medium used by the professoriate to share information}

Table 8 shows the medium used by the professoriate to share their research information. The results show that the vast majority of the professoriate publish their research outcomes in subscription-based (100\%) and fee-based open access $(98.8 \%)$ journals. About eighty $(50 \%)$ of the professoriate publish in no-fee open access journals. 
Table 8 Medium used by the professoriate to share information

\begin{tabular}{lcc|cc}
\hline \multirow{2}{*}{ Medium used by the professoriate to share information } & \multicolumn{2}{|c|}{ Yes } & \multicolumn{2}{c}{ No } \\
\cline { 2 - 4 } & $\mathbf{N}$ & $\%$ & $\mathbf{N}$ & $\%$ \\
\hline I publish in subscription-based journals & 165 & 100 & - & 1.2 \\
I publish in fee-based open access journals & 163 & 98.8 & 2 & 51.5 \\
I publish in no-fee open access journals & 80 & 48.5 & 85 & \\
\hline
\end{tabular}

\subsection{Attitude of the professoriate towards electronic information resources}

The results on attitude of the professoriate towards electronic information resources are captured in Table 9.

Table 9 Attitude of the professoriate towards electronic information resources

\begin{tabular}{|c|c|c|c|c|c|c|}
\hline \multirow{2}{*}{ Attitude of the professoriate } & \multicolumn{2}{|c|}{ Disagree } & \multicolumn{2}{|c|}{ Neutral } & \multicolumn{2}{|c|}{ Agree } \\
\hline & $\mathbf{N}$ & $\%$ & $\mathbf{N}$ & $\%$ & $\mathbf{N}$ & $\%$ \\
\hline $\begin{array}{l}\text { Using electronic information resources saves a lot of time and } \\
\text { effort in research. }\end{array}$ & 2 & 1.2 & - & - & 161 & 97.6 \\
\hline $\begin{array}{l}\text { Electronic information resources are a fast means of getting } \\
\text { information for teaching and research. }\end{array}$ & 6 & 3.6 & - & - & 159 & 96.4 \\
\hline I will like to learn more about electronic information resources. & 5 & 3.0 & - & - & 159 & 96.4 \\
\hline $\begin{array}{l}\text { I like telling my research students to use electronic information } \\
\text { resources. }\end{array}$ & 6 & 3.6 & - & - & 159 & 96.4 \\
\hline $\begin{array}{l}\text { Electronic information resources are an effective tool for teaching } \\
\text { and research }\end{array}$ & 9 & 5.5 & - & - & 156 & 94.5 \\
\hline $\begin{array}{l}\text { Electronic information resources improve my ability to teach and } \\
\text { conduct research }\end{array}$ & 11 & 6.7 & - & - & 154 & 93.3 \\
\hline Electronic information resources make me more productive. & 11 & 6.7 & - & - & 154 & 93.3 \\
\hline $\begin{array}{l}\text { Electronic information resources make my teaching and research } \\
\text { easy. }\end{array}$ & 17 & 10.3 & - & - & 148 & 89.7 \\
\hline $\begin{array}{l}\text { I enjoy using electronic information resources for teaching and } \\
\text { research. }\end{array}$ & 17 & 10.3 & - & - & 148 & 89.7 \\
\hline $\begin{array}{l}\text { I organise my teaching and research work better with the use of } \\
\text { electronic information resources. }\end{array}$ & 24 & 14.5 & - & - & 141 & 85.5 \\
\hline $\begin{array}{l}\text { I like to use electronic information resources for teaching and } \\
\text { research rather than use print resources. }\end{array}$ & 144 & 87.3 & 8 & 4.8 & 13 & 7.9 \\
\hline
\end{tabular}

The overall results suggest the professoriate have a positive attitude towards electronic information resources. A vast majority $(161 ; 97.6 \%)$ of the professoriate are of the opinion that using electronic information resources saves a lot of time and effort in research. Likewise, an overwhelming majority (159; 96.4\%) affirms electronic information resources are a fast means of getting information for teaching and research. The respondents who agreed that they would like to learn more about electronic information resources and those who are likely to tell their research students to use electronic information resources account for 159 (96.4\%), respectively. Many (156; 94.5\%) of the professoriate agreed that electronic information resources are an effective tool for teaching and research as compared to the few (nine; 5.5\%) who disagreed. The respondents who feel electronic information resources improve their ability to teach and conduct research and increase their productive levels are 154 (93.3\%), respectively. Equal (148; 89.7\%) are those whose opinion affirmed that electronic information resources make their teaching and research easy and enjoy using it for teaching and research. I organise my teaching and research work better with the use of electronic information resources got the nod from 141 $(85.5 \%)$ compared to twenty-four $(14.5 \%)$ who did not agree with the statement. The majority $(144 ; 87.3 \%)$ of the professoriate did not agree with the statement, I like to use electronic information resources for teaching and research rather than use print resources, supporting the notion that print resources are preferred. Only thirteen (7.9\%) agreed with the statement.

\section{Discussion}

The understanding of information needs and information seeking behaviour of the professoriate is important in planning, development and implementation of information systems and services that will meet their information seeking patterns. If academic librarians are adequately to serve academic researchers, they must recognise the changing information environment and provide services in accordance with changing needs. Therefore, understanding the information needs 
and information seeking behaviour and attitude of the professoriate is essential to library collection development, improving services and upgrading facilities to meet the professoriate's need for information effectively.

\subsection{Information needs of the professoriate}

The top information needs of the professoriate are information for developing content used for teaching, conducting research, and keeping abreast of current developments in their fields of study. Teaching is a vital part of their professional duty and involves passing acquired knowledge to the intended recipients. These findings are consistent with Tahir, Mahmood and Shafique (2008: 5), where the authors found "teaching or lecture preparation" and "to support research work" to be the main purpose of information seeking. In a similar study, Okonoko, Emeka-Ukwu and Ayomanor (2015) observed that academic faculty members need information for academic purposes, conducting research and selfdevelopment. Likewise, Sujatha (2016) found that faculty seek information to prepare for class lectures, writing and presenting papers, doing research work, and maintaining up-to-date knowledge. Teaching and research are the most important components of career growth in the academy. The professoriate need information to prepare for lectures and conduct research in their respective fields. The need for information to keep abreast of current developments gives the professoriate more grounding and authority in their fields of study.

\subsection{Information sources used by the professoriate}

Online databases and electronic journals are both used in seeking information for teaching and research. Online databases are hosted on websites and can be accessed using the internet usually through a web browser. Some online databases are free while others can be accessed upon payment of a monthly subscription fee. E-journals are scholarly journals that can be accessed via electronic transmission. In other words, e-journals can be housed in databases or on websites and can be downloaded freely or upon payment of the required subscription. In either case, the importance of both information resources to the professoriate for academic and research purposes is greatly emphasised in the findings of this study.

There are several types of online academic databases serving different academic disciplines including the social sciences and humanities. These online databases house many peer-reviewed journals which give them the credibility and authoritativeness fit for teaching and research purposes. The professoriate, being distinguished members of the academy, ought to rely on respected and credible sources, both for quality classroom delivery and excellence in research. An important point to note in this finding is the degree of acceptance and use of online databases and journals by the professoriate. Previous studies (Redmann \& Kotrlik 2004, Waugh 2004, Mumtaz 2000, Budin 1999, Blazek \& Aversa 1994, Stone 1982) have shown that professoriate exhibited anxiety over the use of electronic information resources. The findings of this study show a change towards more acceptance of information technology (online databases and ejournal). Early studies (Blazek \& Aversa 1994, Stone 1982) on information behaviour of faculty members showed that they (including the professoriate) preferred printed resources. For instance, Stone (1982), in an article summing up research published between 1970 and 1982, noted that books and journals were cited as the most frequently-used research material. The dependence on printed sources during this period is linked to an era when the internet was still in its infancy and the development of the internet protocol suite TCP/IP (Transport Control Protocol/Internet Protocol), a standard protocol that allows for internetworking, was still at its developmental stage. Academic libraries in this period acted as the only information source for faculty members and provided only print resources for patrons. Studies conducted during this period reflected the preference for print sources.

In 1990, Sethi studied the information seeking behaviour of 256 social science faculty members in Indian universities and found that faculty members preferred journals, books, government documents and reference sources for meeting their information needs (Sethi 1990). In 1995, in a study on information seeking among social science researchers, Folster (1995) noticed that the study participants had less regard for computer-based services, and preferred books and print journals. Later researchers however, have observed that social science faculty members make wide use of electronic information resources in their research, signifying the impact of information technology in their information behaviour (Shen 2007, Hannah 2005, Meho \& Haas 2001, Costa \& Meadows 2000). Most of the studies conducted in the social sciences and humanities during this period have similar patterns, showing an inclination towards electronic resources among faculty members. The result of this study affirms that the professoriate are embracing technology when seeking information and aligns with recent trends in behavioural change in adopting technology due to its ease and convenience in accessing, sharing and using information.

Although Xumei (2010) showed that history professors relied more on old manuscripts, sometimes dating as far as fifty to 100 years, a study on historians' attitudes toward electronic resources, observed an increased use of online catalogues and indexes in finding information sources (Dalton \& Charnigo 2004). This finding implies that, though disciplinary context could constrain faculty to seek information in a particular medium, their general attitude towards 
electronic information resources is changing. To this end, while investigating differences in culture and discipline in information users, Wang (2006) noted some differences across the two dimensions in the way users rank and use information sources. In this study, the e-journal was rated second in the electronic resources category but was rated third in Xuemei's (2010) study where the author observed that participants (professors and doctoral students) could not make a distinction between e-journals and online databases and were confounded in their choice. The same can be said of this study: even though there was no narrative evidence to support it, the difference between e-journals and online databases remains confusing since, in the majority of cases, users of online databases retrieve e-journals as the end point of their information search.

Journals and textbooks are the most-used print resources by the professoriate for teaching and research. Print resources remain an important information source for teaching and research despite the growing popularity of electronic information resources. The reason for print's continued relevance is due to some obvious factors such as that it is easy to read from and can be conveniently carried about with no risk, unlike with computers and laptops. Findings from studies (Bello 2014, Shen 2007) revealed that, though some professoriate prefer electronic resources for research, they end up printing the content before reading it. Use of print resources has been found to be context-based. Lawyers and historians use print resources more than their counterparts in the sciences and social sciences (Majid \& Kassim 2000). Professoriate in Arabic were observed to rely more on print resources because of the lack of electronic databases in Arabic which limits the availability of electronic resources in that language (Al-Suqri 2011). This finding implies that geographical and cultural factors may influence the nature of resources used for teaching.

A study (Marouf \& Anwar 2010) in the Social Sciences Faculty at Kuwait University confirms this trend, where faculty members depended heavily on books and journals for teaching. A similar study of Spanish faculty members showed participants preferred books to journals and materials in the Spanish language. In other instances, professoriate in the social sciences preferred more print than electronic resources for teaching, and preferred electronic resources over print for research (Khan \& Bhatti 2012, Marouf \& Anwar 2010, Hannah 2005). As noted by Xumei (2010), much of history is not yet documented electronically, making print resources indispensable for historians. Early studies (Blazek \& Aversa 1994, Stone 1982) on information needs show that print sources were mainly used for information seeking. The findings of this study show that, despite the changing trend towards the use of electronic information resources, print resources remain and will continue to have their place of relevance in information seeking. Recent studies (Bello 2014, Folorunso 2014, Khan \& Bhatti 2012, Marouf \& Anwar 2010, Tahir, Mahmood \& Shafique 2008) support this evidence and show that print sources are still very reliable even in the face of growing use of electronic information resources.

\subsection{Professoriate access to information}

The study shows that the professoriate access information for research and teaching from their offices, while a vast majority also access information from their homes. The professoriate that access information from the library are few. The use of an office to access information is expected since the office is their official workspace. After official hours, the office provides an alternative environment for the professoriate to engage in research when not occupied with their families. With the advent of information technology, the professoriate could use either their laptops or office desktop computers to access the university electronic library resources or access other electronic databases via the internet. Like this finding, accessing information from offices by university academics is documented in similar studies (Marouf \& Anwar 2010, Abrahamson \& Fisher 2007).

This study observed that a vast majority of the professoriate access information from their homes. This implies that most of them may have their personal libraries at home that provide them with the private space they need for maximum concentration and optimal intellectual output. Work that is not finished at the office might be completed at home; this work includes lecture preparation and research engagement. The results of the study show that the professoriate make less use of the library to access information for teaching and research purposes. This result is not entirely surprising as most of their time is spent at the office and at home, and they may want their private space, which the university library may not provide. Similar to what was observed in this study, Xuemei (2010) and Folorunso (2014) noted poor use of the library by the professoriate.

\subsection{Professoriate information sharing}

Professoriate information sharing was measured by the types of information shared by the professoriate and the medium used to share research outcomes. The following segments are the discussions based on the findings.

\subsubsection{Types of information shared by the professoriate}

The result on the type of information shared by the professoriate shows that a vast majority of the professoriate frequently share research and academic information. It is not surprising that research and academic information are the most 
frequently shared information by this group. Teaching and research are the main task of the professoriate and engaging in them is fundamental to their productivity and growth in academia. Sharing political information comes next and denotes how engaged the professoriate could be in political matters. Political information sharing most often comes in the form of debates and ideological viewpoints. This sort of non-academic discourse is very common among the academia especially when they gather in informal sessions; it is not expected that it should only occur occasionally as evidenced by the findings of this study.

Social and economic information follow a similar pattern: shared occasionally by the professoriate. Sharing social information emphasises the importance of social ties among the professoriate and within the academic community, suggesting that the professoriate are non-exclusive of their social world and their keen participation in social life is a vital part of their total well-being despite their academic status. Moreover, economic information, occasionally shared by the professoriate shows their keen interest and value for economic indicators and measurements vital in assessing the economic world. Since the professoriate have high earning potential, investment in the economy is a sustainable strategy to become financially independent both in the short and long run. Therefore, being aware of what is happening in their economic environment becomes an innate desire that prompts information seeking, and economic information sharing becomes a pattern towards satisfying such a need. Legal, business, personal, medical and technical information needs are rarely shared by the majority of the professoriate, showing that kind of information is less important in the view of the majority of the professoriate.

\subsubsection{Medium used by the professoriate to share information}

The majority of the professoriate publish their research outcomes in subscription-based and fee-based open access journals, while about half of the professoriate publishes in no-fee open access journals. Conducting research is part of the academic requirements of the professoriate and publishing their research outcomes is a crucial step to ensure their visibility and relevance. Publishing also offers a way of sharing scientific discoveries in the academic community and beyond. Without visibility of research outcome, the value of the entire research process is highly diminished. Research is beneficial if the outcome is published in a scholarly journal for public consumption. Visibility of empirical research brings economic gains to both the academic institution and the professor that carried out the research, and forms part of the yardstick used in the evaluation and ultimately in the ranking of the university against other universities nationally and globally.

Professoriate in this study currently prefer publication in subscription-based journals and fee-based open access journals. This finding is not surprising especially considering the fierce competition for academic positions in Nigerian universities. Becoming a member of the professoriate requires a certain amount of publishing, and once attained, the status demands prolific research and publication. Subscription-based journals encompass both top ranking and low impact journals and charge a subscription fee (individuals or universities) to access either the print or electronic versions. With subscription-based journals, both the content and the review process are handed over to the publishing house and payment is made for publication. In some instances, universities pay subscription fees to a plethora of journals for easy access by staff and students. The recent decade has seen the rise of open access journal publications, which still offer peer-reviewed scientific publication but with a different business model to the more traditional subscription-based journals. The open access approach rests on online publishing. Open access journals are divided into those that charge publication fees and those that do not. Fee-based open access journals require payment by the author. The money might come from the author but more often comes from the authors' research grant or employer. On the other hand, the no-fee open access journals enable completely free access to the scientific community and to the public. In open access journals, accepted manuscripts are published online much faster than their subscription-based counterparts.

\subsection{Attitude of the professoriate towards electronic information resources}

The professoriate in this study had a positive attitude towards electronic information resources with regards to teaching and research. 'Attitude toward using technology' refers to an individual's overall affective reaction to using a system and is defined as the degree to which an individual believes he or she should use a particular system (Venkatesh et al. 2003). 'Attitude' refers to a person's favourable or unfavourable evaluation of an object, denoting that it places individuals on a bipolar affective dimension (Fishbein and Ajzen 1975). Looking at the items that measured the attitude scale, we can see a 'bipolar affective dimension'. For instance, the statements, I enjoy using electronic information resources for teaching and research, Electronic information resources are a fast means of getting information for teaching and research and Electronic information resources make my teaching and research easy, could be evaluated based on the professoriate's favourable or unfavourable disposition towards the measurement item, thereby satisfying the 'bipolar affective' requirement of the attitude construct. 
Similar to the findings of this study, other studies (Liu et al. 2010, Lee 2009, Benamati \& Rajkumar, 2008, Yousafzai, Foxall \& Pallister 2007) have provided adequate support for the significant influence of ease of use of technology on attitude, supporting the evidence that the professoriate in this study exhibited a favourable disposition towards use of electronic information resources on account of its ease of use. Behavioural theories (Venkatesh and Davis 2000, Davis, Bagozzi \& Warshaw 1992, Ajzen 1991, Fishbein \& Ajzen 1975) posit that positive attitude leads to behavioural actions. Many instructional technologies may exist to enhance higher education but can only be used by faculty members if they possess the skills, knowledge and attitudes necessary to embed them into the curriculum (Baylor \& Ritchie 2002). To this end, Alhabi (2014) pointed out that successful implementation of information technologies in education depends on the attitude of the educators who ultimately decide its use in the teaching process. Consistent with this study, other studies (Bamibgola 2014, Goharinezhad, Faraji \& Jameie 2012, Owolabi \& Ajiboye 2012) have acknowledged the positive attitude of faculty members in using institutional digital repositories for teaching and research. The findings also tally with Surej's (2015) view that, if faculty members have a positive attitude towards using computers for teaching and learning, they will be more satisfied and effective users of electronic resources.

\section{Conclusion and recommendations}

The study examined the information seeking behaviour of the professoriate in three federal universities in Nigeria, with the aim of discovering their information needs, how they seek, access and share information, and their attitude towards electronic information resources. The study found that information behaviour of the professoriate is characterised, among others, by the need for information for teaching and research and keeping abreast of developments in their fields. The professoriate has a positive attitude towards the use of electronic resources, reflected in its high use of electronic journals and online databases for teaching and research. Despite the professoriate's inclination towards electronic information resources, print resources have proved indispensable as a resource used for teaching and research due to ease and simplicity of use.

Information technology has a major impact on the professoriate's information behaviour. Use of desktop computers and laptops coupled with access to the internet have altered conventional information seeking patterns, making it possible for the professoriate to access information from their offices and conveniently take their laptops home and continue with office work, accessing online digital resources and the institutional online repository while logged-on to the internet. The resultant effect of the flexibility and convenience associated with information technology is depicted in low patronage of the university library by the professoriate. The professoriate frequently shares research and academic information and occasionally shares political, social and economic information. It prefers to publish research outcomes in subscriptionbased and fee-based open access journals as opposed to no-fee open access journals.

The study makes the following recommendations based on its findings. Since the professoriate makes less use of the university library, the creation of a dedicated and well-furnished space which is comfortable and equipped with uninterrupted internet and power supply for ease of access to print and electronic information resources could encourage the professoriate to make use of the university library. Since the professoriate still relies on textbooks for teaching and research, the space will create a conducive environment for study and reference to both print and electronic information resources. There is a need for the university library to acquire up-to-date collections to address the academic and research needs of professoriate in different disciplines and to create a system that can inform the professoriate of recent collections in their fields. Such a system could use short message service (SMS) or email as information alerts or reminders. Lastly, the outcomes of the study will guide the formulation of institutional policy into being cognisant of the observed characteristics inherent in the professoriate's information behaviour to guide the academic library in the development of a service and system framework that focuses on meeting its unique information requirements. Lastly, the acceptance of electronic information resources and related technologies by the professoriate has far-reaching implications. It predicts the future trajectory in an information space where technology-complacent individuals will have no choice but to conform to innovations or lose out in a world where education advances are to a large extent driven by technology.

\section{Acknowledgement}

The financial assistance of the National Institute for the Humanities and Social Sciences Council for the Development of Social Science Research in Africa (NIHSS-CODESRIA) towards this research is hereby acknowledged. Opinions expressed and conclusions arrived at are those of the authors and are not necessarily to be attributed to the NIHSSCODESRIA. 


\section{References}

Abrahamson, J. and Fisher, K.E. 2007. What's past is prologue: towards a general model of lay information mediary behaviour. Information Research, 12(4): 65-72.

Aforo, A.A. and Lamptey, R.B. 2012. Information needs and seeking behaviour of law lecturers in Kwame Nkrumah University of Science and Technology, Kumasi, Ghana. International Research Journal of Arts and Social Sciences, 1(4): 75-80.

Ajzen, I. 1991. The theory of planned behaviour. Organizational Behaviour and Human Decision Processes, 50: 179-211.

Alhabi, H. 2014. Towards successful implementation of ICT in education. The 2014 WEI International Academic Conference Proceedings. 13-15 April 2014. Vienna, Austria: WEI International Academic. [Online]. https://www.westeastinstitute.com/wp-content/uploads/2014/05/Hanaa-Eid-Al-harbi-Full Paper.pdf (6 July 2018).

Al-Suqri, M.N. 2011. Information-seeking behaviour of social science scholars in developing countries: A proposed model. The International Information and Library Review, 43: 1-14.

Bamibgola, A.A 2014. Surveying attitude and use of institutional repositories (IRs) by faculty in agriculture disciplines. Procedia - Social and Behavioral Sciences, 147(2014) 505-509.

Baylor, A. L. and Ritchie, D. 2002. What factors facilitate teacher skill, teacher morale, and perceived student learning in technology-using classrooms? Computers and Education, 39: 395-414.

Bello M.A., 2014. Information seeking behaviour and use of social scientists in selected universities in southwest Nigeria. IOSR Journal of Humanities and Social Science 19(8): 67-74.

Benamati, J.S. and Rajkumar, T.M. 2008. An outsourcing acceptance model: an application of TAM to application development outsourcing decisions. Information Resources Management Journal, 21(2): 80-102.

Bhatti, R. 2010. Information needs and information-seeking behaviour of faculty members at the Islamia University of Bahawalpur. Library Philosophy and Practice (e-journal), Paper 314. [Online]. http://digitalcommons.unl.edu/libphilprac/314 (13 June 2015).

Blazek, R. and Aversa, E. 1994. The humanities: a selective guide to information resources. 4th ed. Englewood, CO: Libraries Unlimited.

Bronstein, J. 2010. Selecting and using information sources: source preferences and information pathways of Israeli library and information science students. Information Research, 15(4): paper 447. [Online]. http://InformationR.net/ir/154/paper447.html (8 July 2018).

Budin, H. 1999. The computer enters the classroom. Teachers College Record, 100(3): 656-669.

Carrell, S.E. and West, J.E. 2010. Does professor quality matter? Evidence from random assignment of students to professors. Journal of Political Economy, 118(3): 409-432.

Costa, S. and Meadows, J. 2000. The impact of computer usage on scholarly communication among social scientists. Journal of Information Science, 26(4): 255-62.

Dalton, M. and Charnigo, L. 2004. Historians and their use of information sources. College and Research Libraries, 65(5): 400-25.

Davis, F.D., Bagozzi, R.P. and Warshaw, P.R. 1992. Extrinsic and intrinsic motivation to use computers in the workplace. Journal of Applied Social Psychology, 22(14): 111-1132.

De Groote, S.L., Shultz, M. and Blecic, D.D. 2014. Information-seeking behaviour and the use of online resources: A snapshot of current health sciences faculty. Journal Medical Library Association, 102 (3). [Online]. https://www.ncbi.nlm.nih.gov/pmc/articles/PMC4076125/ (25 June 2015)

Engel, D., Robbins, S. and Kulp, C. 2011. The information-seeking habits of engineering faculty. College and Research Libraries, 72(6): 548-567.

Ezeh, A. N. 2013. Extension agents access and utilization of information and communication technology (ICT) in extension service delivery in South East Nigeria. Journal of Agricultural Extension and Rural Development, 5(11): 266-276.

Ezinwanyi, M. and Opeke, R. 2013. Information needs and seeking behaviour of senior non academic staff in Nigerian Universities. Journal of Humanities and Social Science, 7(6): 1-8.

Fishbein, M., and Ajzen, I. 1975. Belief, attitude, intention and behaviour: an introduction to theory and research. Reading, MA. :Addison-Wesley

Folorunso, O. 2014. Information-seeking behaviour of social sciences scholars: a Nigerian case study. African Journal for the Psychological Study of Social Issues, 17(2). [Online]. http://www2.marilia.unesp.br/revistas/index.php/bjis/article/view/5218/3670 (25 June 2015).

Folster, B. M. 1995. Information-seeking patterns: social sciences. The Reference Librarian, 49(50): 83-93.

Goharinezhad, S. Faraji, Z. and Jameie, B. 2012. Knowledge, attitude and practice of faculty members on integrated digital library (IDL) in Tehran University of Medical Sciences. International Journal of Digital Library Services, 2(4): $51-62$.

Hannah, F. 2005. The information-seeking behaviour of social faculty at the University of West Indies, St Augustine Campus. Journal of Academic Librarianship, 31(1): 67-72.

Hemminger, B.M., Lu, D., Vaughan, K.T.L. and Adams, S.J., 2007. Information seeking behaviour of academic scientists. Journal of the American Society for Information Science and Technology, 58(14): 2205-2225.

Ismail, M., Mahesar, R.A. and Idrees, M. 2017. Electronic Information Source (EIS) preferences by faculty members at the University of Peshawar. Grassroots, 51(1), 282-295. 
Khan, G and Bhatti, R, 2012. Information needs and seeking behavior of law faculty members: a survey of the University of Peshawar and its Affiliated Law Colleges. Library Philosophy and Practice (e-journal). 786. [Online]. http://digitalcommons.unl.edu/libphilprac/786 (18 May 2015).

Laila, M. and Mumtaz, A.A. 2010. Information seeking behaviour of the social science faculty at Kuwait University. Library Review, 59(7): 532-547.

Larbi-Apau, J.A. and Moseley, J.L. 2012. Computer attitude of teaching faculty: implications for technology-based performance in higher education. Journal of Information Technology Education: Research, 11:221-233.

Lee, M. 2009. Factors influencing the adoption of internet banking: an integration of TAM in the acceptance of information technologies. Decision Sciences, 28(3): 557-582.

Liu, I.F., Chen, M.C., Sun, Y.S., Wible, D. and Kuo, C.H. 2010. Extending the TAM model to explore the factors that affect Intention to use an online learning community. Computers \& Education, 54(2): 600-610.

Majid, S. and Kassim, G.M. 2000. Information seeking behaviour of International Islamic University Malaysia law faculty members. Malaysian Journal of Library and Information Science, 5(2): 1-17.

Majid, S., Ali Anwar, M. and Eisenschitz, T.S., 2000. Information needs and information seeking behaviour of agricultural scientists in Malaysia. Library \& Information Science Research, 22(2): 145-163.

Marouf, L. and Anwar, M.A. 2010. Information-seeking behavior of the social sciences faculty at Kuwait University. Library Review, 59(7): 532-547.

Meho, L.I. and Tibbo, H.R. 2003. Modelling the information behaviour of social scientists: Ellis's study revisited. Journal of the American Society for Information Science and Technology, 54(6): 570-587.

Meho, L.I. and Haas, S.W. 2001. Information seeking behaviour and use of social science faculty studying stateless nations: a case study. Library and Information Science Research, 23: 5-25.

Mumtaz, S. 2000. Factors affecting teachers' use of information and communications technology: a review of the literature. Journal of Information Technology for Teacher Education, 9(3): 319-342.

Nigeria Universities Commission. 2015. Nigeria Universities Commission. [Online] http://www.nuc.edu.ng (10 June 2015).

Ofori-Dwumfuo, G.O. and Addo, L. 2012. Utilization of information and ICT resources by parliamentarians in Ghana. Current Research Journal of Social Science, 4(3): 213-221.

Okonoko, V.N., Emeka-Ukwu, U. and Ayomanor, K.E. 2015. Information seeking behaviour of faculty members in a Nigerian university. International Journal of Academic Research and Reflection, 3(4): 95-102.

Owolabi and Ajiboye 2012. Use of Electronic Information Sources (EIS) by faculty members in Nigerian Universities. Library Philosophy and Practice. [Online]. https://digitalcommons.unl.edu/cgi/viewcontent.cgi?article=1795\&context=libphilprac (8 July 2018).

Redmann, D.H. and Kotrlik, J.W. 2004. Analysis of technology integration in the teaching-learning process in selected career and technical education programs. Journal of Vocational Education Research, 29(1): 3-25.

Rupp-Serrano, K. and Robbins, S. 2013. Information seeking habits of education faculty. College \& Research Libraries, 74(2): 131-141.

Salau, E.S. and Saingbe, N.D. 2008. Access and utilization of information and communication technologies (ICTs) among agricultural researchers and extension workers in institutions in Nasarawa State of Nigeria. PAT, 4(2): 1-11. [Online]. http://patnsukjournal.net/Vol4No2/p1.pdf (15 June 2015).

Savolainen, R. 2011. Elaborating the motivational attributes of information need and uncertainty. Information Research, 17(2): paper 516. [Online]. http://InformationR.net/ir/17 2/paper516.html (8 July 2018).

Savolainen, R. and Kari, J. 2004. Placing the internet in information source horizons. A study of information seeking by internet users in the context of self-development. Library and Information Science Research, 26(4): 415-433.

Sethi, A. 1990. Information-seeking behaviour of social scientists: an Indian conspectus. New Delhi: Hindustan Publishing Corporation.

Shadish, W., Cook, T.D. and Campbell, D.T. 2002. Experimental and quasi-experimental designs for general causal inference, Boston: Houghton Mifflin.

Shen, Y. 2007. Information-seeking in academic research: a study of the sociology faculty at the University of Wisconsin, Madison. Information Technology and Libraries, 26(1): 4-13.

Singh, K.P and Satija, M.P. 2007. Information seeking behaviour of agricultural scientists with particular reference to their information seeking strategies. Annals of Library and Information Studies, 54: 213-220.

Stone, S. 1982. Humanities scholars: information needs and uses. Journal of Documentation, 38: 292-313.

Sujatha, S. 2016. Exploring information seeking behaviour in the changing ICT environment: a snapshot of Kakatiya university faculty. International Journal of Information Services and Technology, 1(1): 11-15.

Surej, P.J. 2015. The integration of information technology in higher education: a study of faculty's attitude towards IT adoption in the teaching process. Contaduría y Administración, 60(1): 230-252.

Tahir, M. Mahmood, K. and Shafique, F. 2008. information needs and information-seeking behavior of arts and humanities teachers: a survey of the University of the Punjab, Lahore, Pakistan. Library Philosophy and Practice (ejournal). 227. [Online]. http://digitalcommons.unl.edu/libphilprac/227 (25 September 2016).

Thanuskodi, S. 2009. Information-seeking behaviour of law faculty at Central Law College, Salem. Library Philosophy and Practice (e-journal), Paper 282. [Online]. http://digitalcommons.unl.edu/libphilprac/282 (24 May 2015).

Theall, M. and Franklin, J. 2001. Looking for bias in all the wrong places: A search for truth or a witch hunt in student ratings of instruction? New Directions for Institutional Research, 109: 45-56. 
Ugah, A.D. 2008. Availability and accessibility of information sources and the use of library services at Michael Okpara University of Agriculture. Library Philosophy and Practice. [Online]. http://www.webpages.uidaho.edu/ mbolin/ugah4.pdf (15 June 2015).

Venkatesh, V. and Davis, F.D. 2000. A theoretical extension of the Technology Acceptance Model: four longitudinal field studies. Management Science 46(2): 186-204.

Venkatesh, V., Morris, M.G., Davis, G.B., and Davis, F.D. 2003. User acceptance of information technology: toward a unified view. MIS Quarterly, 27(3): 425-478.

Wang, P. 2006. Information behaviours of academic researchers in the internet era: an interdisciplinary \& cross-cultural study. Paper presented at the $1^{\text {st }}$ International Scientific Conference eRA: the Information Technology to Science, Economy, Society \& Education. 16-17 September 2006.

Alhabi, H. 2014. Towards successful implementation of ICT in education. The 2014 WEI International Academic Conference Proceedings. 13-15 April 2014. Vienna, Austria: WEI International Academic. [Online]. https://www.westeastinstitute.com/wp-content/uploads/2014/05/Hanaa-Eid-Al-harbi-Full Paper.pdf (6 July 2018).

Waugh, W.L. 2004. Using personal attributes to predict technology adoption: a study of college faculty. NABTE Review, 31: 58-63.

Wilson, T.D. 2000. Human information behaviour. Special Issues on Information Science Research, 3(2): 49-55.

Xuemei, G. 2010. Information-seeking behaviour in the digital age: a multidisciplinary study of academic researchers. College and Research Libraries 34(2): 435-452.

Yousafzai, S.Y., Foxall, G.R. and Pallister, J.G. 2007. Technology acceptance: a meta-analysis of the TAM: Part2, Journal of Modelling in Management, 2(3): 281-304. 